\title{
Servikal miyelopati: laminektomi ve laminoplasti
}

\author{
Cervical myelopathy: laminoplasty and laminectomy
}

\author{
Ümit Özgür Güler, Metin Özalay
}

Başkent Üniversitesi Adana Araştırma ve Uygulama Hastanesi, Ortopedi ve Travmatoloji Bölümü, Adana

\begin{abstract}
Servikal spondilotik miyelopati birçok nedenle ortaya çıkabilen cerrahi bir patolojidir. Füzyon ile veya füzyonsuz olarak laminoplasti ve laminektomi, çoklu seviye servikal spondilotik miyelopati tedavisinde sıklıkla kullanılan posterior prosedürlerdir. Laminoplasti; servikal hareketlerin korunduğu, spinal kordun indirekt olarak dekompresyonunun sağlandığı, laminanın menteşe şeklinde bir taraf veya her iki taraftan açılması ile spinal kordun anterior bası yapan yapılardan uzaklaştırıldığı bir tekniktir. Bu bölümün amacı, laminoplasti ve laminektominin avantaj ve dezavantajlarının, önemli cerrahi teknik basamaklarına değinilerek tartışılmasıdır.
\end{abstract}

Anahtar sözcükler: servikal spondilotik miyelopati; cerrahi; posterior; laminektomi; laminoplasti
Cervical spondylotic myelopathy (CSM) is a commonly encountered surgical disease that may occur for a variety of reasons. Laminoplasty and laminectomy with or without fusion are two common posterior procedures for the treatment of multilevel CSM. Laminoplasty is a technique that indirectly decompresses the spinal cord and preserves neck motion by hinging the laminae open on one or both sides, to allow the spinal cord to migrate posteriorly away from anterior compressive structures. The goal of this chapter is to discuss the advantages and disadvantages of laminoplasty and laminectomy by referring to the key technical points regarding different surgical techniques of these procedures.

Key words: cervical spondylotic myelopathy; surgery; posterior; laminectomy; laminoplasty ervikal miyelopati (SM), servikal omuriliğin kompresyonuna bağlı gelişen semptom ve bulguların oluşturduğu kliniği tanımlar. Konjenital veya akkiz bilinen birçok nedenle, kanal basısı ve miyelopati oluşabileceği gibi yaşa bağlı olarak da servikal disfonksiyon gelişebilir. SM, yaşlı nüfustaki spinal disfonksiyonun, travmatik olmayan spastik paraparezinin ve kuadriparezinin en sık nedenidir. Kliniğin erken dönemlerinde miyelopatik hastanın bulguları sessiz olması nedeniyle, genellikle tanı kolayca gözden kaçabilir veya yaşlanmanın normal bir getirisi olarak düşünülerek, herhangi bir girişim yapılmaz. Ancak bununla birlikte, doğal seyirin tipik olarak patolojinin aşamalı ilerlemelerin basamaklarından olması nedeniyle, geri dönüşü olmayan spinal kord hasarının başlangıcından önce optimal sonuçlar için erken tanı ve tedavi şarttır. Altta yatan nedene bağlı olarak, spinal kord basısı sonrası üst ekstremite kuvvetsizliği ve parestezisi, el beceri kaybı, yürüyüş bozukluğu, barsak ve mesane disfonksiyonları gibi klinik durumlara yol açar. Eğer patolojik süreç foraminal etkilenmeye de neden olmuşsa, ağrı ve duysal motor kayıplarının eşlik ettiği radiküler bulgularla birlikte görülebilir.

Cerrahi tedavide amaç, servikal spinal kanal ekspansiyonunun yeterince sağlanabilmesidir. $\mathrm{Bu}$, kordon ve spinal köklerin dekompresyonunu sağlayarak statik ve dinamik faktörler tarafından daha fazla sıkışmasını önler. İkinci amaç, kordun makaslama hasarlanmaları ile oluşmuş anormal segmental hipermobilitenin iyi şekilde füzyonunu sağlayarak, ileride oluşabilecek geç spinal deformitenin önlenmesidir. Son amaç ise, patolojik süreç ile gelişmiş ağrının azaltılmasıdır.

\section{SM'de Cerrahi Endikasyonlar ve Yaklaşım; Anterior veya Posterior?}

Cerrahi tedaviye karar verirken değerlendirmemiz gerekenler; servikal omurganın dizilimi (lordotik, kifotik veya düz); deformitenin sertliği (sert veya yumuşak); kliniği neden olan patolojinin nedeni (konjenital, akkiz,

- Illetişim adresi: Prof. Dr. Metin Özalay, Dadaloğlu Mah. 2591 Sok. No:4/A, Yüreğir, Adana

Tel: 0541 - 6379898 e-posta: metinozalay@gmail.com

- Geliș tarihi: 5 Nisan 2017 Kabul tarihi: 5 Nisan 2017 
veya dejeneratif); statik veya mobil subluksasyon varlığı; hastanın medikal durumu ve aksiyel boyun ağrısı varlı̆̆ıdır.

Cerrahi tedavinin planlanmasında, her hasta için ayrıntılı olarak tartışılmış ve kişiselleştirilmiş tedavi tercih edilmeli; hastanın patoanatomisi, nörolojik durumu, medikal komorbiditeleri, seçilecek girişime özgül riskler ve cerrahın tecrübesi göz önüne alınarak karar verilmelidir. Spinal darlığın servikal bölgede kliniğe neden olabilmesi için: aksiyel kesitte yapılan ölçümlerde kanal genişliği $13 \mathrm{~mm}$ ise spondiloz ile birlikte miyelopati görülme riski varken, $10 \mathrm{~mm}$ ve altında spondiloz ve miyelopati sıklıkla görülür. Genellikle cerrahi tedavi;

1) ilerleyici nörolojik bulguları olan,

2) altı ay ve daha uzun süren miyelopati kliniği olan,

3) kanal kompresyon oranı 0,4 veya transvers kanal alanı $40 \mathrm{~mm}^{2}$ veya daha az olan ciddi spinal kord kompresyonu tespit edilen hastalara uygulanmaktadır.
Ayrıca, günlük aktivitelerini veya işini engelleyen klinik bulguları olan hastalara da tedavi seçenekleri arasında cerrahi düşünülmelidir. Literatürde, 80 yaş üstü aktif hastalarda üç aydan daha kısa süreli yürüyememe ve semptomların başlangıcının üç yıldan daha az olduğu durumlarda cerrahi yapılabileceğini belirten çalışmalar olduğu gibi, konservatif tedaviye yanıt vermeyecek hastalarda da cerrahinin uygun olabileceğini belirten çalışmalar da mevcuttur. ${ }^{[1,2]}$

Cerrahide genel olarak; anterior, posterior veya çevresel olmak üzere çeşitli yaklaşım şekil ve kombinasyonları bulunmaktadır (Şekil 1). Anterior yaklaşımda, anterior servikal diskektomi ve füzyon veya anterior servikal korpektomi ve füzyon; posterior yaklaşımda ise laminektomi veya laminoplasti ile füzyon uygulanabilir. Cerrahide anterior veya posterior yaklaşımı belirleyen en önemli faktör sagittal dizilimdir. Özellikle, kifoz varlığında posterior cerrahi tercih edilmez. Bir diğer önemli kriter ise spinal darlığın lokasyonudur. Dar kanal, faset artropatisi ve/veya hipertrofisi, ligamentum flavum hipertrofisi gibi klinik patolojilere bağlı gelişmiş

\section{OMURILIK BASISI}
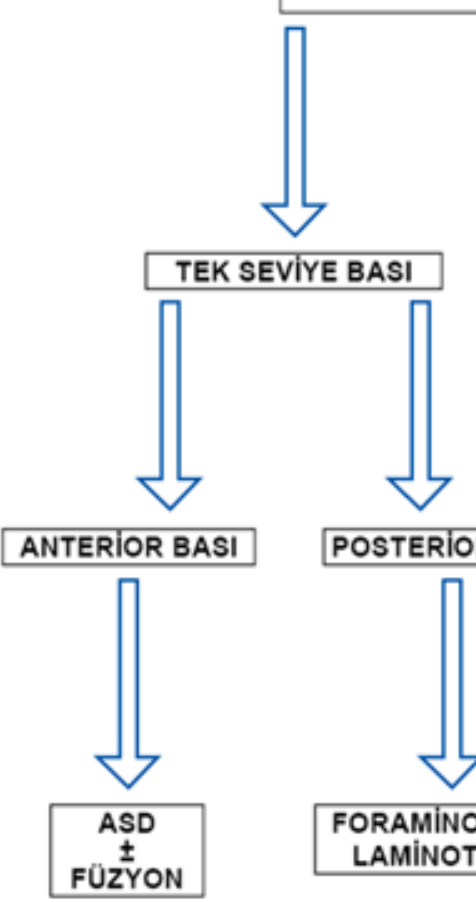

ASD: Anterior Servikal Dekompresyon ASDF: Anterior Servikal Dekompresyon ve Füzyon

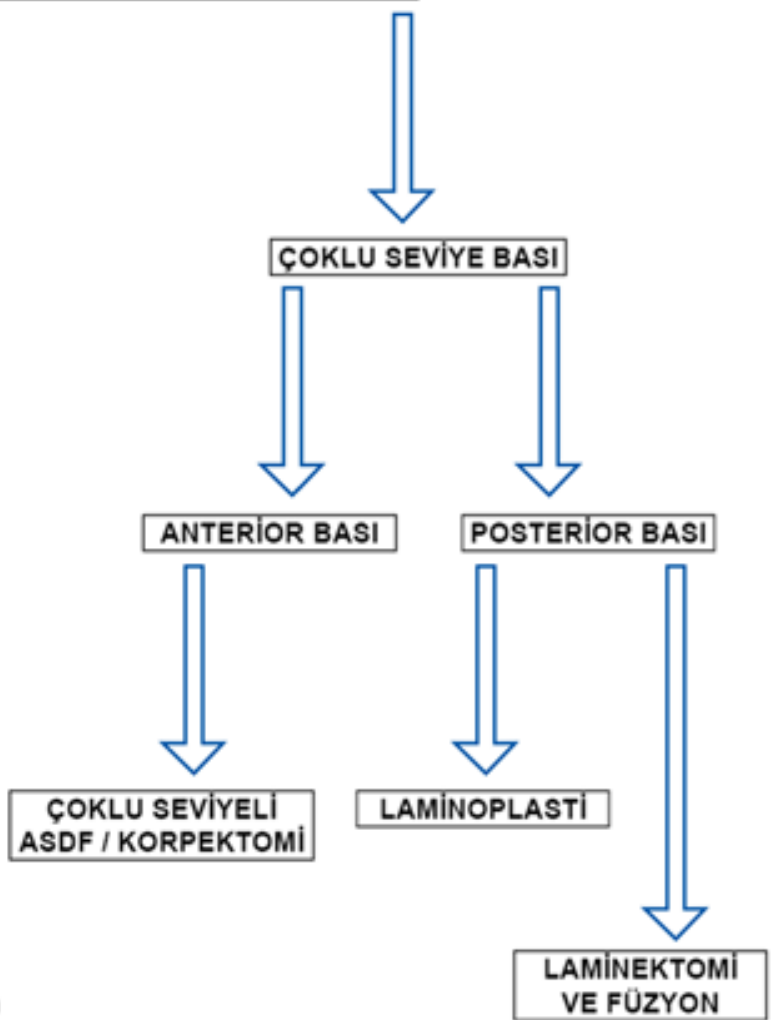

Şekil 1. Spinal kanal basısına göre cerrahi modelleme. (Dr. Selçuk Palaoğlu arşivinden alınmıştır) 
ise posterior yaklaşım; öte yandan, spinal kanal basısı disk hernisi veya omur cismi osteofitinden kaynaklanıyorsa anterior yaklaşım tercih edilir. Girişim metodu tercihine ek olarak, cerrahi öncesi değerlendirmede statik lateral servikal radyografide $3,5 \mathrm{~mm}$ 'den fazla subluksasyon varlığı, ardışık segmentte $11^{\circ}$ 'den fazla açılanma olması ve dinamik grafilerde $4 \mathrm{~mm}$ 'den fazla subluksasyon görülmesi durumlarında, cerrahiye servikal füzyonun da eklenmesi önerilir. ${ }^{[3]}$

Posterior cerrahinin avantajlarına bakıldığında en önemlisi, bu girişim şeklinin sıklıkla yapılması ve aşina olunmasıdır. Çoklu seviye laminektomi sıklıkla yapılmakla birlikte, diğer girişim yöntemlerine göre; teknik olarak daha kolay, daha kısa zamanlı ve daha az komplikasyon görülen girişim metodudur. Ancak bunlarla birlikte, posterior yaklaşımın en önemli sınırlaması nöral yapıların indirekt dekompresyonudur. Ventral patolojide cerrahi başarı, nöral elemanların dorsal translasyonuna bağlıdır. Özellikle düz veya kifotik dizilim varlığında, ventral patoloji tedavisinde uygulanan posterior cerrahi ek nörolojik patolojilere neden olabilir. Ayrıca posterior girişim, paraspinal kas innervasyonlarına neden olması nedeniyle cerrahi sonrası boyun ağrılarına neden olabilir. Bununla birlikte, posterior cerrahi C5 sinir kökünde parsiyel disfonksiyona ve dissosiyatif motor kayba neden olabilir. Literatürde, C5 sinir kökünün disfonksiyonu \%1,4-23 ve ortalama her iki cinsiyette eşit olarak $\% 7,8$ oranında görülür. ${ }^{[4]}$ Özellikle, C5 kökü ile ilgili bu kliniğin çıkmasına birçok neden sayılabilir. Örneğin; hastada kliniğe bağlı gelişmiş iskemi varlığının, C5-C6 kökünün anatomik varyasyonlarının dekompresyon sonrası duraya doğru hareketlenmesinden dolayı olduğu öne sürülmüş, ancak hiçbiri ispatlanamamıştır. Literatür değerlendirilmesinde, C5 sinir kökü palsisinin görülme nedenlerine bakıldığında; patolojinin anatomik ve klinik seyrinin, örneğin OPLL (ossifiye posterior longitudinal ligament)'de servikal spondilotik miyelopati veya servikal disk hernisine göre daha sıklıkla görülebileceği, yine mevcut foraminal stenoz varlığında görülme olasılığının artacağı öngörülmektedir. Ayrıca, servikal dizilimin fazla miktarda değiştiği, özellikle servikal lordozun arttırıldığı olgularda, daha sıklıkla görülebileceği belirtilmektedir. ${ }^{[4,5]}$

\section{LAMINEKTOMI VE LAMINOPLASTI}

Laminektomi SM'nin özgün tedavi şeklidir. Servikal lateral mass ve laminalar, laminektominin lateral kesilerinin sınırını belirler. Eğer klinik olarak foraminal darlık da mevcut ise cerrahiye foraminotomiler de eklenmelidir. Literatürde yapılan çalışmalarda, faset eklemlerin \%25'inden fazlasının eksize edilmesinin spinal kolon fleksibilitesinde artışa neden olacağı ve instabilite oluşabileceği öngörülmüştür. Oluşan kifoz, laminektominin iyi bilinen komplikasyonlarındandır. Ayrıca, laminektomi sonrası dura üzerinde oluşan membran yapının, daha sonra olgunlaşarak dural skar formasyonuna neden olabileceği; bunun da, sonrasında tekrarlayan kord basısına yol açarak, geç nörolojik bozulmalara neden olabileceği bildirilmiştir.

Laminoplasti, anterior dekompresyon ve füzyon, posterior laminektomi ve füzyon gibi servikal bölge cerrahilerinin görülen komplikasyonları nedeniyle, bu tekniklere alternatif olarak geliştirilmiş bir cerrahi tekniğidir. Laminoplastide amaç; laminayı yeniden şekillendirerek spinal kanal çapını arttırmak, dorsal elemanları koruyarak durada skar dokusu oluşumunu engellemek ve cerrahi sonrası servikal stabilite ve dizilimin korunmasının sağlamaktır. Füzyon gerekmemesi nedeniyle; fiksasyon yetmezliği, psödoartroz, hareket kaybı ve ardışık seviye dejenerasyonu gibi fiksasyona bağlı komplikasyonlar görülmez. Ayrıca, diğer cerrahi tekniklere göre daha erken mobilizasyon ve rehabilitasyona izin verir. Bununla birlikte, laminoplastide genellikle greft kullanılmadığı için, greft çıkması, çökmesi, kırılması gibi komplikasyonlar da görülmez.

Laminoplasti, çoklu seviye SM tedavisinde laminektominin yerine ve ayrıca, uzun segment servikal dar kanallarda anterior yaklaşıma alternatif olarak kullanılabilen bir yöntemdir. Endikasyonları, üç veya daha fazla disk alanını içeren santral stenozun neden olduğu SM veya miyeloradikülopatidir. Bu klinik durum; çoklu seviye dejeneratif servikal spondiloz, OPLL, çoklu seviye disk herniyasyonu, servikal spinal tümörler, akut travmatik santral kord sendromu veya gelişimsel servikal stenoz gibi patolojiler ile oluşabilir. Laminoplastinin kontrendikasyonuna bakıldığında da, kifotik deformite varlığı en önemlisidir. Kifotik deformitede, yapılacak bir laminoplasti anteriordan kord basısını engelleyemeyecek, kanal ekspansiyonunda meydana gelen azalma kordun dorsale migrasyonuna neden olacaktır. Bununla birlikte, gelişebilecek spinal instabilite kifozu daha da arttıracaktır.

Laminektominin aksine, laminoplastide yük taşımak için posterior lamina ve paraspinal kas yapışma yerleri korunur. Ligamentum flavum da korunmuş olur. $\mathrm{Bu}$, instabiliteyi azaltır ve füzyon için ortam hazırlar. Ayrıca, laminanın korunması ile ekstradural skar oluşumu da azaltılmış olur. Çalışmalar, tek veya çift kapı laminoplasti sonuçlarının nörolojik iyileşme açısından eşit olduğunu göstermektedir.

Laminektomi veya laminoplasti sonrası enstrümantasyonlu veya enstrümantasyonsuz füzyon, ciddi aksiyel boyun ağrısı ve segmental instabilitesi olan 
hastalarda endikedir. Enstrümantasyon ise, erken dönem stabilite sağlayarak füzyon oranlarını arttırır. Sublaminar teller, interspinöz cihazlar, plaklar, lateral mass veya pedikül vidaları, kullanılabilen enstrüman materyalleridir.

\section{LAMINOPLASTI TEKNIKLERI}

İlk laminoplasti, OPLL için tedavisi yapılmış olan bir olgunun 1973 yılında yayımlanması ile popülarize olmuştur. ${ }^{[6]}$ illk tanımlamada; servikal spinöz proçesler alınmış, lamina faset birleşiminden inceltilmiş, ardından laminaya Z şeklinde kesi yapılarak açılmış sütür veya tel yardımı ile kemikler fikse edilmiştir. Illk özgün tarifinden bugüne, kemik kesi şekli veya sabitleme materyalleri değiştirilerek, laminoplastide birçok teknik tanımlanmıştır. Hemen hemen tüm tekniklerde amaç, laminanın yeniden şekillendirilmesine bağlı olarak spinal kanalda elde edilen ekspansiyon ve dorsal kemik elemanların, dolayısıyla stabilitenin korunmasıdır. Tüm tekniklere bakıldığında, klinik sonuç anlamında hiçbiri diğerine üstünlük sağlayamamıştır. Teknikleri üç başlık altında toplayabiliriz: açık kapı (open door), iki kapı (double door) ve çeşitli kas koruyucu laminoplasti (muscle-sparing).

\section{Genişletici Açık Kapı Laminoplasti (Hibayashi, Açık-Menteşe, Tek-Kapı Tekniği)}

Hibayashi, 1980'lerde, lamina kesisini tek taraflı ekspansil açık kapı laminoplastisi şeklinde tanımlamıştır. Bu teknikte menteşe, laminanın bir tarafında, lamina - spinöz çıkıntı - ligamentum flavum kompleksi üzerinde oluşturulur. Bu, kanal çatısının karşı tarafa doğru açılması ve kanalın ekspanse olmasını sağlar.

Açık kapı laminoplasti genelllikle C2-C7 seviyeleri arasında yapılır ve tüm seviyelerde kemik yapılar ortaya konulur. Orta hat insizyonu, oksipital çıkıntıdan T1 spinöz çıkıntıya kadar yapılır. Orta hat fasya ve ligamentum nuchae açılarak, C2-T1 arası seviyeler hazırlanır. Proksimal ve distal bölümlerde, supraspinöz ve infraspinöz bağlar korunmaya çalışılmalıdır. Ayrıca, C2 seviyesinde cerrahi sonrası kifoz deformitesi oluşmasını engellemek amacıyla, kas bağlantıları da korunmalıdır. Eğer C2-C3 seviyesinde dekompresyon gerekiyorsa, C2 kas bağlantıları, daha sonra yeniden sütüre edilecek şekilde C2 dorsal elemanlarından ince bir osseöz parça ile ayrilabilir. Orta hat insizyonu, subperiostal olarak paravertebral kasların disseksiyonu ve kasların laterale alınarak kemik yapıların fasetin mediyaline kadar ortaya konulması ile tamamlanır. Eğer füzyon planlanmıyorsa, faset kapsülleri korunmalıdır. Laminoplastide açılacak taraf olarak, daha çok radiküler semptomun ve stenozun olduğu taraf tercih edilmelidir. Kontrollü şekilde burr veya yüksek devirli kesici yardımı ile, tüm laminalar rostralden kaudale doğru laminaya dik olacak şekilde, her lamina superior sınırında daha dikkatli olunarak, dekortike edilmelidir. Sonrasında, incelen laminanın kesilecek tarafı 2-3 mm Kerrison Rongeur yardımı ile pediküllerin 2-3 mm mediyalinden yapılmalı, menteşe olarak kullanılacak taraf ise, yine yüksek devirli burr ile dış kortekste kesi oluşturacak şekilde, yeşil ağaç kırığı biçiminde hazırlanmalıdır. Lamina hareketlenmesini takiben kemik yapıyı açık olarak tutmak için, Hirabayashi kendi özgün tekniğinde, sütür ankor ile kemik yapıyı spinöz çıkıntıdan menteşe olarak hazırlanan taraftaki faset kapsülüne sabitlemiştir. Daha sonraki çalışmalarda, kemik yapının açık kalması için titanyum mini-plaklar, çelik teller, faset kabloları, seramik implantlar, kemik ankorlar ile birlikte oto- ve allogreftler kullanılmıştır (Şekil 2 ve 3).

\section{İki Kapı Laminoplasti \\ (Double-Door, French-Door, T-Saw, Spinöz Çıkıntı Ayrılma, Orta Hat Ayrılma)}

Kurokawa tarafından, 1982 yılında tanımlanmıştır. Orta hatta iki lamina yarısı, ligamentum flavum ve spinöz çıkıntı kompleksi sağ ve sol simetrik parça şeklinde osteotomize edilerek yapılan laminoplasti şeklidir. Açık kapı laminoplastisinde olduğu gibi, kemik yapı hazırığını takiben burr ve Kerrison Rongeur yardımı ile spinöz çıkıntı ortadan ayrılarak, lamina ve ligamentum flavuma kadar osteotomi işlemi yapılmasını takiben, her iki spinöz çıkıntı arasına lamina ayırıcı konularak kanal dekompresyonu sağlanır. Her iki spinöz çıkıntı, sütür ankorlar ile faset kapsüllerine sabitlenir. Mevcut iki kemik arasındaki alan için birçok materyal kullanılabilmektedir (örneğin; seramik/hidroksiapatit veya iliak/ kosta otogreftleri). Bu laminoplastinin avantajı, posteriordan direkt bir dekompresyon sağlanması nedeniyle, kanama miktarının diğer yöntemlere göre daha az olmasıdır. Ancak bu yöntemde, spinöz çıkıntı kesisi sırasında duranın hasarlanma riski, açık kapı laminoplastiye göre daha fazladır. Ayrıca, Tomita bu yöntemin modifikasyonunda, lamina superioru ve inferiorundan epidural alana polietilen bir kılavuz yerleştirmiş ve spinöz çıkıntıyı orta hattan ayırmak için bunun üzerinden gigli telini kullanmış; bu yönteme de T-Saw laminoplasti adını vermiştir.

\section{Kas Koruyucu Laminoplasti Teknikleri}

Laminoplasti sonrasında görülebilen, aksiyel boyun ağrısı, cerrahi sonrası kifoz ve segmental instabilite gibi komplikasyonların, cerrahi sırasında yapılan kas disseksiyonlarına bağlı olduğu düşünülmektedir. Bu nedenle kas disseksiyonunu en aza indiren çeşitli teknikler tanımlanmıştır. 

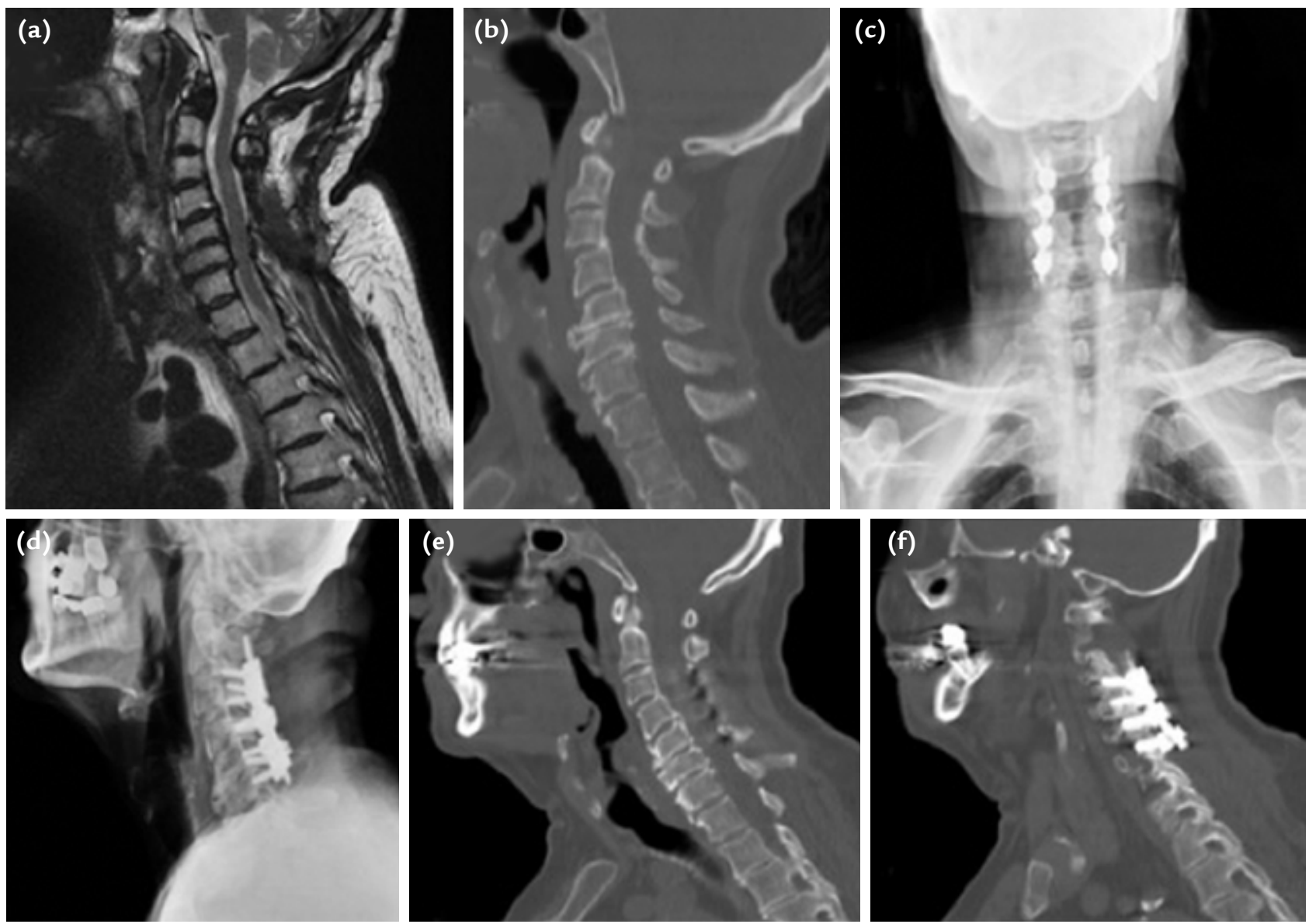

Şekil 2. a-f. Altmış beş yaşında erkek hastaya; servikal dar kanal nedeniyle, üç seviye laminektomi ve posterior stabilizasyon ve füzyon uygulanmış.
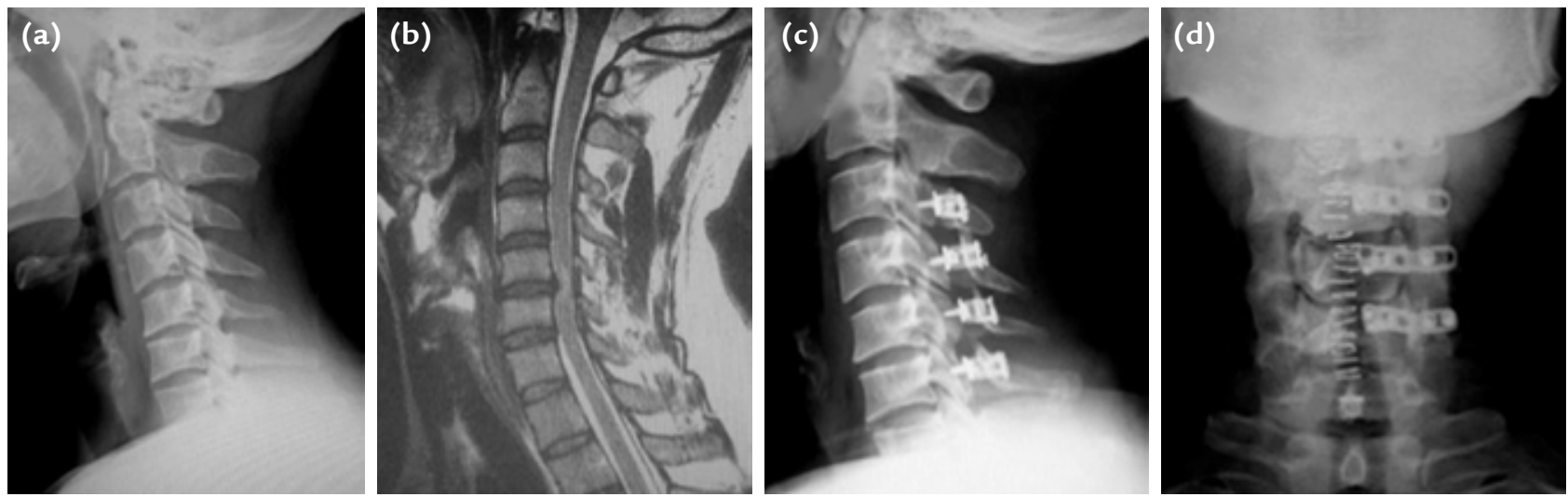

Şekil 3. a-d. Kırk iki yaşında erkek hastada; tespit edilen SM'ye yönelik yapılan laminoplasti sonrası grafileri. (Dr. Mehmet Aydoğan arşivinden alınmıştır)

Shirashi, derin ekstansör, semispinalis servisis ve multifidus kas gruplarına daha az zarar verecek tekniği tanımlamıştır. Yazar, mikroskop altında, cerrahi planlanan seviye üzerinden yapılan orta hat insizyonu sonrası spinöz çıkıntılardan, interspinalis, semispinalis servisis ve spinöz çıkıntıya yapışan multifidus kaslarını disseke ederek, bu kas grupları arasından girilerek lamina ulaşma ve sonrasında iki kapı laminoplasti yapılmasını önermektedir. Bunun gibi bazı çalışmalarda, diğer bir aksiyel boyun ağrısı nedeni olarak, C7'ye 
yapışan musküloligamentöz yapıların cerrahi sırasında destrükte edilmesi olduğu belirtilmiştir. C7'nin, ekstansör kasların kaldıraç mekanizmasının önemli bir bileşeni ve böylelikle servikal dizilimin de önemli parçası olduğu belirtilerek, cerrahi sırasında bu bölgeye yapışan trapezius, rhomboid minor ve nuchal ligamenti koruyan yöntemler önerilmiştir. ${ }^{[4,5]}$

\section{SONUÇ}

Sonuç olarak; servikal dejeneratif sorunlar, değerlendirilmesi ve cerrahi tedavisi özel ilgi gerektiren patolojilerdir. Hastanın cerrahisinde; tüm klinik iyi bir şekilde, öykü, fizik muayene ve radyolojik olarak değerlendirilmeli, en az komplikasyona neden olabilecek cerrahi prosedür anterior-posterior girişim olarak ve en önemlisi cerrahın da tecrübesine göre belirlenerek uygulanmalıdır.

\section{KAYNAKLAR}

1. Matz PG, Anderson PA, Holly LT, Groff MW, Heary RF, Kaiser MG, Mummaneni PV, Ryken TC, Choudhri TF, Vresilovic EJ, Resnick DK; Joint Section on Disorders of the Spine and Peripheral Nerves of the American Association of Neurological Surgeons and Congress of Neurological Surgeons. The natural history of cervical spondylotic myelopathy. J Neurosurg Spine 2009;11(2):104-11. Crossref

2. Tanaka J, Seki N, Tokimura F, Doi K, Inoue S. Operative results of canal-expansive laminoplasty for cervical spondylotic myelopathy in elderly patients. Spine (Phila $\mathrm{Pa}$ 1976)1999;24(22):2308-12.

3. Epstein N, Epstein JA. Treatment of cervical myelopathy: Part A. Laminectomy. In: TCSR Society, editor. The cervical spine. Philadelphia: Lippincott Williams \& Wilkins; 2005. p.1043-56.

4. Pan FM, Wang SJ, Ma B, Wu DS. C5 nerve root palsy after posterior cervical spine surgery. J Orthop Surg (Hong Kong) 2017;25(1):2309499016684502. Crossref

5. Guzman JZ, Baird EO, Fields AC, McAnany SJ, Qureshi SA, Hecht AC, Cho SK. C5 nerve root palsy following decompression of the cervical spine: a systematic evaluation of the literature. Bone Joint J 2014;96-B(7):950-5. Crossref

6. Oyama M, Hattori S, Moriwaki N. A new method of cervical laminoplasty. Cent Jpn J Orthop Traumat Surg 1973;16:792-4. 